\title{
ANTIDIABETIC ACTIVITY OF NANOPARTICLES CONTAINING JAVANESE TURMERIC RHIZOME EXTRACT: THE STRATEGY TO CHANGE PARTICLE SIZE
}

\author{
DENI RAHMAT ${ }^{1 *}$, YUNAHARA FARIDA ${ }^{1}$, AVILLA TAN BRYLIANTO' ${ }^{1}$, ROS SUMARNY ${ }^{1}$, SHIRLY KUMALA ${ }^{1}$
}

1Faculty of Pharmacy, Pancasila University, Srengseng Sawah, Jagakarsa, Jakarta Selatan 12640, Indonesia

Email: denrerum@gmail.com

Received: 02 Nov 2019, Revised and Accepted: 11 Apr 2020

\section{ABSTRACT}

Objective: The aim of this study was to investigate the antidiabetic activity of Javanese turmeric rhizome extract and its nanoparticles. Javanese turmeric rhizome contains curcumin, flavonoid, and xanthorrhizol that show the antidiabetic activity. The plant extracts entrapped within the nanoparticles have been reported to increase the active compound bioavailability. Thereby, the nanoparticles can improve the biological activity of active compounds.

Methods: The rhizome was extracted by kinetic maceration using $96 \%(\mathrm{v} / \mathrm{v})$ ethanol, whereas the nanoparticles were prepared by the ionic gelation method with different formulations to obtain two types of nanoparticles (F1 and F2). The resulting nanoparticles were evaluated for their particle size, zeta potential, and morphology. The antidiabetic study was performed in a model of alloxan-induced diabetic mice. The mice were divided into five groups, namely normal, negative, positive, extract (dose of $400 \mathrm{mg} / \mathrm{kg}$ ) and nanoparticles group (dose of $400 \mathrm{mg} / \mathrm{kg}$ ). Afterward, the blood glucose levels were observed within $24 \mathrm{~d}$ using a glucometer.

Results: The nanoparticles F1 displayed particle size of $157.8 \pm 18.0 \mathrm{~nm}$ with a polydispersity index of 0.488 and zeta potential of $+51.4 \pm 4.56 \mathrm{mV}$. Spray drying process of the suspension of nanoparticles F1 produced a fine yellow powder. In contrast, nanoparticles F2 assembled with a different solvent system gave rise to a smaller particles size $(90 \pm 20.8 \mathrm{~nm})$ but could not be dried. Hence, the nanoparticles F1 were further studied for the antidiabetic study. The results showed that the nanoparticles; F1 rendered a better antidiabetic activity compared to the extracts. Percentage of decrease in blood glucose levels of the extract and the nanoparticles were 39.62 and $47.52 \%$, respectively.

Conclusion: The type of solvent system of the extract could interfere with the resulting particle size of the nanoparticles. The nanoparticles could be promising carriers for the extract to improve the antidiabetic activity.

Keywords: Javanese turmeric rhizome, Curcumin, Extract, Nanoparticles, Antidiabetic

(C) 2020 The Authors. Published by Innovare Academic Sciences Pvt Ltd. This is an open access article under the CC BY license (http://creativecommons.org/licenses/by/4.0/) DOI: http://dx.doi.org/10.22159/ijap.2020v12i4.36249. Journal homepage: https://innovareacademics.in/journals/index.php/ijap

\section{INTRODUCTION}

Diabetes mellitus is the third leading cause of death in Indonesia with $6.7 \%$ after stroke and coronary heart disease. The number of diabetic patients also continues increasing and increasingly alarming. It was estimated that the number of diabetics patients will continue jumping, from $2.8 \%$ of the world's population in 2000 to $4.4 \%$ by $2030[1,2]$.

One of the methods that can be used to treat patients with diabetes mellitus is medicinal plants consumption. Many treatments use medicines from natural ingredients $[3,4]$. One of the medicinal plants that have the efficacy as antidiabetic is turmeric rhizome that possesses many beneficial compounds. One of the compounds is curcumin. Several scientific studies have demonstrated the pharmacological potential of curcumin, including antioxidants, antiinflammatory, and antitumor. In addition, Javanese turmeric rhizome also contains xanthorrizol which is proven to lower blood glucose levels in alloxan-induced mice. This potential is related to hyperglycemia, which is one of the initial abnormal conditions of the homeostasis of blood glucose that can lead to the occurrence of diabetes mellitus of type 2 [5].

The extract of medicinal plants can be formulated into pharmaceutical dosage form through nanotechnologies. Furthermore, nanotechnology has been developed and applied to improve the permeation of the bioactive compounds of various extracts. The extract can be entrapped within the nanoparticles to improve their stability and bioavailability. Thereby, their biological activities could be optimized due to the increased blood level of the active compounds [6-8]. Therefore, it was the aim of the study to evaluate antidiabetic activity of Javanese turmeric rhizome extract entrapped within the nanoparticles in a model of alloxan-induced diabetic mice. Two different formulations of the nanoparticles were applied to the extract and their characterization was investigated.

\section{MATERIALS AND METHODS}

\section{Materials}

Javanese turmeric rhizome, adult male mice (Mus musculus L.) DDY strain, chitosan (Biotech Surindo), dimethyl sulfoxide (DMSO), sodium tripolyphosphate (Na TPP) (Hubei Xingfa Chemical), propylene glycol, ethanol, capmul, alloxan tetrahydrate and glibenclamide (PT Indofarma, Indonesia).

\section{Methods}

\section{Preparation of extract}

Javanese turmeric rhizome was identified by The Center for Plant Conservation Botanic Garden-Indonesian LIPI with the authentic number is B-112/IPH.3./KS/I/2018. The specimen was deposited in Herbarium of Pharmacognocy Laboratory, Faculty of Pharmacy, Pancasila University $(1 / \mathrm{DR} / \mathrm{HLF} / \mathrm{UP})$. The rhizomes were cleaned with water and dried in the dark. After drying, the rhizomes were powdered and extracted by maceration using $96 \%$ (v/v) ethanol as a solvent as described in the previous studies [9]. The mixture of maceration was then filtered. The filtrate was collected and concentrated by rotary vapor. Phytochemical screening was carried out to find out the secondary metabolic compounds in the extract [9].

\section{Preparation of nanoparticles F1}

The ethanolic extract was dissolved in the mixture of solvent $(20 \mathrm{ml}$ propylene glycol, $20 \mathrm{ml} 70 \%(\mathrm{v} / \mathrm{v}$ ) ethanol, $20 \mathrm{ml} \mathrm{10 \%} \mathrm{(v/v)} \mathrm{DMSO}$ and $100 \mathrm{ml}$ distilled water). $1 \%(\mathrm{w} / \mathrm{v})$ chitosan solution in glacial acetic acid was mixed with the extract solution in the final concentration of $0.2 \%(\mathrm{w} / \mathrm{v})$. The mixture was stirred using a magnetic stirrer of $300 \mathrm{rpm}$ for $10 \mathrm{~min}$. afterward, $20 \mathrm{ml} 0.4 \%$ (v/v) $\mathrm{Na}$ TPP solution was added dropwise at a rate of $1 \mathrm{drop} / 3 \mathrm{sec}$ to the final mixture under permanent stirring of $300 \mathrm{rpm}$ [10]. 


\section{Preparation of nanoparticles F2}

Preparation of nanoparticle F2 was carried out as described previously with slightly modification. $1 \mathrm{~g}$ of chitosan was dissolved in $100 \mathrm{ml} 1 \%$ $(\mathrm{v} / \mathrm{v})$ glacial acetic acid using a magnetic stirrer to obtain a concentration of $1 \%(\mathrm{w} / \mathrm{v})$. A total of $500 \mathrm{mg}$ of Javanese turmeric rhizome extract was added to the mixture consisting of $5 \mathrm{ml}$ capmul, $10 \mathrm{ml} 70 \%$ (v/v) ethanol, $10 \mathrm{ml}$ propylene glycol, $5 \mathrm{ml}$ glycerin, $5 \mathrm{ml}$ tween 80 , and $5 \mathrm{ml}$

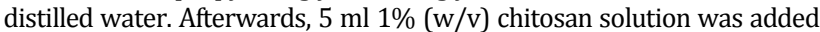
to the extract solution to obtain a concentration of $0.1 \%(\mathrm{w} / \mathrm{v})$. The final mixture was stirred using a magnetic stirrer for $10 \mathrm{~min} .5 \mathrm{ml} 0.2 \%$ (w/v) $\mathrm{Na}$-TPP were added dropwise to the final mixture at a rate of $1 \mathrm{drop} / 3 \mathrm{~s}$ under a permanent stirring of $300 \mathrm{rpm}$ to form nanoparticles with homogeneous turbidity [9].

\section{Evaluation of nanoparticles}

Particle size and zeta potential value of the resulting nanoparticles was determined by particle and zeta sizer, while the morphologies study was carried out by transmission electron microscopy (TEM) and scanning electron microscopy (SEM). $1 \mathrm{ml}$ the nanoparticles were diluted with 99 $\mathrm{ml}$ distilled water before all the evaluations. The suspension of nanoparticles was observed for its stability within $5 \mathrm{~d}$, including color, turbidity and sedimentation. The stable nanosuspension was then dried using a spray dryer at an inlet temperature of 185 and $195^{\circ} \mathrm{C}$. The dried powder was used for the morphology study using SEM and antidiabetic activity evaluation $[9,10]$.

\section{Antidiabetic activity study}

Antidiabetic activity study used male mice DDY strains (3-4 w old) with weights ranging from 21 to $26 \mathrm{~g}$ (mean weight of $23 \mathrm{~g}$ ). The mice were bred in the animal house at Laboratory of Non-Ruminansia and Hope Animal, Faculty of Animal Husbandry, Bogor Agricultural University, Indonesia. The mice were acclimatized for $7 \mathrm{~d}$ to laboratory conditions $\left(25 \pm 2{ }^{\circ} \mathrm{C}\right)$ with $12 \mathrm{~h} / 12 \mathrm{~h}$ darkness photoperiod at Faculty of Pharmacy, Pancasila University, Indonesia. The mice were kept in cages ( 5 mice per cage randomly) and had free access to standard pellet and water. The experimental protocols and procedures used in this study were approved by the Ethics Committee for Health Research (no: KET-929/UN2. F1/ETIK/PPM.00.02/2019) of Medical Faculty of Universitas Indonesia, Indonesia. Afterward, the mice were measured for blood glucose levels before and after alloxan administration (hyperglycemia condition) at the dose of $200 \mathrm{mg} / \mathrm{kg}$ body weight intraperitoneally for $3 \mathrm{~d}$, and after the treatment $(\mathrm{d} 0, \mathrm{~d} 10, \mathrm{~d} 17$ and $\mathrm{d}$ 24), the blood glucose levels of the mice measured by blood sampling from the tail vein of the mice were determined using a glucometer.

All mice were divided into 5 groups and each group consisted of 5 mice which were taken randomly and treated as follows: group 1 as normal control without any treatment; group 2 as positive control treated with glibenclamide at the dose of $0.52 \mathrm{mg} / 20 \mathrm{~g}$ body weight; group 3 as a negative control treated with distilled water using the alloxan-induced diabetic mice; group 4 treated with the extract at the dose of $400 \mathrm{mg} / \mathrm{kg}$ body weight; and group 5 treated with the nanoparticles at the dose of $400 \mathrm{mg} / \mathrm{kg}$ body weight [11,12].

\section{Statistical analysis}

The results that met the requirements were then processed by the statistical analysis method of one-way variation (ANOVA). The obtained significant difference was further analyzed using the MannWhitney test.

\section{RESULTS AND DISCUSSION}

\section{Preparation of extract}

The extract was viscous with rendement as reported previously and could harden in the storage at the temperature of $4{ }^{\circ} \mathrm{C}$. Phytochemical screening was performed to determine the secondary metabolite in the simplicia powder and in the extract. The results indicated that the powder and the extract contained flavonoid, saponin, steroid/triterpenoid and essential oil [9].

\section{Preparation of nanoparticles F1}

The extract was soluble in the mixture of propylene glycol, ethanol and DMSO. The ratio of each solvent resulted in dielectric constant value, which could break the extract into molecules of the compounds. The extract was even more soluble in the presence of a chitosan solution. After adding Na TPP solution, the color of the final solution changed due to the nanoparticles formation.

\section{Preparation of nanoparticles F2}

Capmul, glycerin and tween 80 could be used to replace DMSO for solubilization of the extract. Capmul is mono-diglyceride, which is an excellent solvent for organic compounds, including the extract. In addition, tween 80 and glycerine are capable of dissolving the nonpolar substances in the extract, which could render the formation of small particles. The extract solution of F2 was more viscous than that of F1. Hence, it could inhibit the interaction between the chitosan solution and Na TPP solution. There was no significant change in color of the mixture of extract solution of F2 and the chitosan solution after the addition of Na TPP solution.

\section{Evaluation of nanoparticles}

The nanoparticles F1 and F2 were stable within $5 \mathrm{~d}$ and were evaluated for their particle size and zeta potential. The results are shown in table 1.

Table 1: Characterization of the nanoparticles F1 and F2

\begin{tabular}{lll}
\hline Parameters & F1 $^{*}$ & F2 $^{*}$ \\
\hline Particle Size (nm) & $157.8 \pm 18.0$ & $93.90 \pm 20.8$ \\
Polydipersity index & $0.488 \pm 0.08$ & $0.564 \pm 0.14$ \\
Zeta potential (mV) & $+51.4 \pm 4.56$ & $-0.55 \pm 0.14$ \\
\hline
\end{tabular}

Notes: *Data represented as mean $\pm \mathrm{SD}(\mathrm{n}=3)$

The nanoparticles F1 and F2 demonstrated 157.8 and $93.9 \mathrm{~nm}$ in particle size, respectively indicating that the extract was entrapped within the nanoparticles with the particle size in nano scale. The particle size of F1 was bigger than that of F2 due the difference in the used solvents. The mixture of capmul, tween 80 and glycerine was able to solubilize the multicomponents of extract and resulted in the viscous solution of extract. Thereby, the nanoparticles F2 was slowly formed. In addition, as an excellent solvent, capmul could break the big particles formed when the drops of Na TPP solution were added to the mixture of extract and chitosan solution.

A zeta potential measurements can predict the storage stability of colloidal dispersions. In general, particles aggregation are less likely to occur in charged particles (having high zeta potential) due to electrical repulsion. Generally, zeta potential values above $30 \mathrm{mV}$ (both positive and negative) will form a more stable nanoparticles suspension because the repulsion between particles prevents aggregation [9]. In contrast, low zeta potential can cause the aggregation of particles. The charges on the surface of the nanoparticles will affect its distribution in the body and influence the uptake of nanoparticles into the cells. The cell membranes have negative charges, therefore, the positively charged nanoparticles will have a stronger electrostatic affinity [9]. The result showed that the nanoparticle F1 and F2 exhibited zeta potential of +51.4 and- $0.55 \mathrm{mV}$, respectively. The nanoparticles $\mathrm{F} 1$ could be more stable in aqueous medium compared to the nanoparticles F2, which could not be dried using spray dryer. Thereby, the nanoparticles F1 was used for further studies.

After drying, the nanoparticles F1 had a water content of $9.47 \%$ and a yellow color. The results of the morphological evaluation of 
nanoparticle suspension using TEM and SEM can be seen in fig. 1 and 3 , respectively. Polymer-based drug delivery systems takes a chance in many ways for improving the efficacy of active compounds. The biodegradable polymers have the advantage of their metabolites elimination by genuine metabolic processes [12].

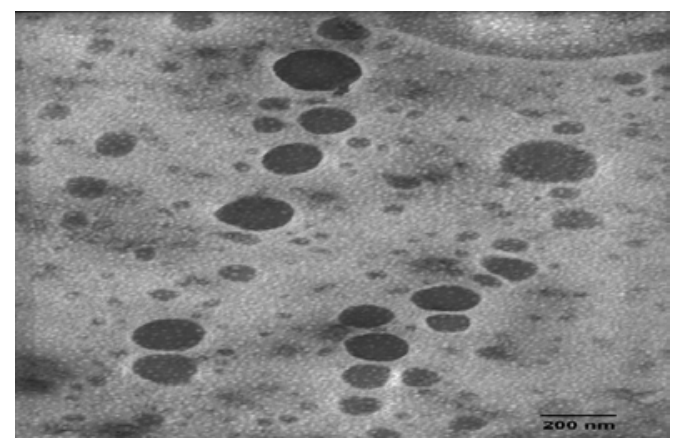

Fig. 1: Morphology of the nanoparticle F1 using TEM

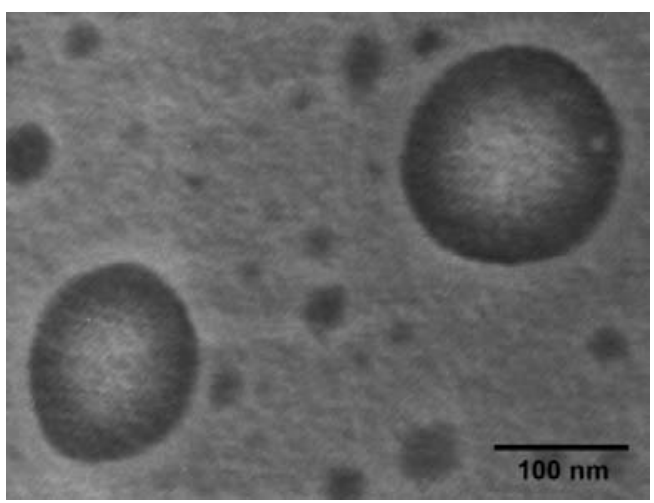

Fig. 2: Morphology of the nanoparticle F2 using TEM

\section{Antidiabetic study}

There was a weight loss in all groups except the normal group on day 10 in hyperglycemic conditions. This is because the need of energy could not be fulfilled by glucose metabolism of the body. This condition could be caused by damage in pancreatic $\beta$ cells due to alloxan administration. Number of studies showed that alloxan administration in mice can increase blood glucose levels [13]. After being given treatment for $14 \mathrm{~d}$, positive control, extract and the nanoparticles F1 were able to increase insulin secretion, to improve insulin receptor sensitivity and to repair the damage of pancreatic $\beta$ cells, thus decrease the blood glucose level. The other studies showed that the extract of medicinal plant treated rats displayed a significant decrease in the lipid content when compared with diabetic induced rats $[14,15]$.

To determine the effectiveness of treatment on mice, the percentages of decrease in blood glucose level in mice treated after 7 $\mathrm{d}(17 \mathrm{~d})$ and $14 \mathrm{~d}(24 \mathrm{~d})$ were calculated. The percentage of decrease in blood glucose levels can be seen in table 2 .

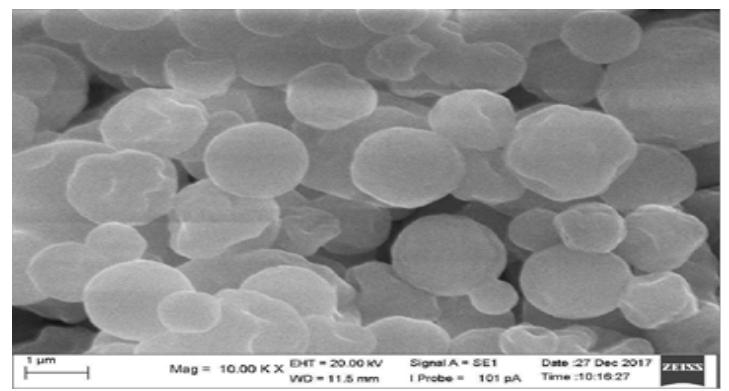

Fig. 3: Morphology of the nanoparticles F1 using SEM (mean \pm SEM, $n=3$ )

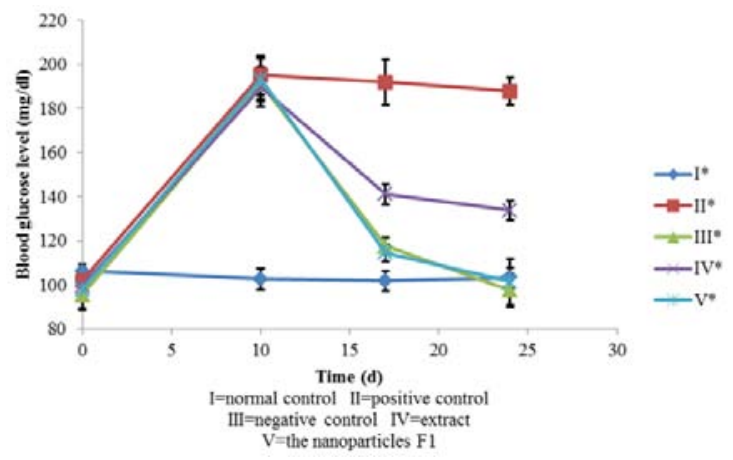

Fig. 4: Blood glucose levels before and after the treatment ( ${ }^{*}$ Data represented as mean $\pm S D, n=5$ )

Table 2: The percentage of decrease in blood glucose levels of mice after the treatment

\begin{tabular}{lll}
\hline Group & \multicolumn{2}{l}{ The percentage decrease (\%) } \\
\cline { 2 - 3 } & $\mathbf{D ~ 1 7}^{*}$ & D 24 $^{*}$ \\
\hline Normal control & $3.12 \pm 4.04$ & $3.31 \pm 3.03$ \\
Negative control & $2.05 \pm 0.49$ & $4.92 \pm 4.45$ \\
Positive control & $38.49 \pm 4.02$ & $48.95 \pm 5,31$ \\
Extract & $25.61 \pm 1.53$ & $39.62 \pm 2,31$ \\
The nanoparticles F1 & $30.75 \pm 1.34$ & $47.52 \pm 6.03$ \\
\hline
\end{tabular}

Notes: *Data represented as mean \pm SD $(n=3)$

During the $7 \mathrm{~d}$ of treatment (day 10) there was a decrease in blood glucose levels of mice in three groups, positive control, extract, and the nanoparticles F1 as depicted in fig. 4. It can be seen that glibenclamide (positive control) can decrease blood glucose levels of the hyperglycemia mice by $38.49 \%$ while extract and the nanoparticles $\mathrm{F} 125.61 \%$ and $30.75 \%$, respectively.

After $14 \mathrm{~d}$, the decrease of the blood glucose level of the mice was comparatively high in the positive control (48.95\%), extract (39.62\%), and the nanoparticles F1 (47.52\%). Based on the results of statistical tests, there was a significant difference between extract and the nanoparticles F1 so that it can be assumed that the nanoparticles F1 had the ability to lower blood glucose levels of mice better than the activity of the extract. The nanoparticles F1 could reach the organ target, whereas chitosan in the nanoparticles F1 could protect the active compounds against the degradation in the body and has mucoadhesive properties [10]. The results of this study indicate that the nanoparticles prepared with Na TPP-chitosan carrier had better antidiabetic activity compared to the extract. These results showed the similarities with previous studies that compared the antidiabetic activity of catharantus roseus extract and nanoparticles containing catharantus roseus extract [11]. The nanosystem, such as liposomes, microemulsion, and the other nanoparticles, is used to improve oral 
drug delivery. The nanoparticles have been used to enhance the permeation of glucose and to prolong the action of active compounds. Many studies have been demonstrated how to encapsulate the drugs into an encapsulation system to enhance the bioavailability subsequently showed better relative pharmacological efficacy [16].

\section{CONCLUSION}

The nanoparticles with a dose of $400 \mathrm{mg}$ extract/ $\mathrm{kg}$ body weight showed higher activity in lowering the blood glucose levels in the alloxan-induced diabetic mice compared to the extract. Therefore, the nanoparticles seems to be a promising strategy to deliver the extract to the target organ.

\section{ACKNOWLEDGMENT}

The author gratefully acknowledge financial support from Ristek DIKTI Indonesia (PDUPT)

\section{AUTHORS CONTRIBUTIONS}

All the authors have contributed equally.

\section{CONFLICT OF INTERESTS}

The authors report no conflicts of interest.

\section{REFERENCES}

1. Purnamasari D. The emergence of non-communicable disease in Indonesia. Acta Med Indones Indones J Intern Med 2018;50:273-4.

2. Wild S, Roglic G, Green A, Sicree R, King H. Global prevalence of diabetes: estimates for the year 2000 and projections for 2030 . Diabetes Care 2004;27:1047-53.

3. Kooti W, Farokhipour M, Asadzadeh Z, Ashtary Larky D, Asadi Samani M. The role of medicinal plants in the treatment of diabetes: a systematic review. Electron Physician 2016;8:1832-42.

4. Ekor M. The growing use of herbal medicines: issues relating to adverse reactions and challenges in monitoring safety. Front Pharmacol 2014;4:1-10.

5. Zhang DW, Fu M, Gao SH, Liu JL. Curcumin and diabetes: a systematic review. Evid Based Complementary Alternat Med 2013:1-16. Doi:10.1155/2013/636053
6. Silva SBD, Amorim M, Fonte P, Madureira R, Ferreira D, Pintado $\mathrm{M}$, et al. Natural extracts into chitosan nanocarriers for rosmarinic acid drug delivery. Pharm Biol 2015;53:642-52.

7. Liu Y, Feng N. Nanocarriers for the delivery of active ingredients and fractions extracted from natural products used in traditional Chinese medicine (TCM). Adv Colloid Interfac 2015;221:60-7.

8. Kwon TK, Kim JC. In vitro skin permeation and anti-atopic efficacy of lipid nanocarriers containing water-soluble extracts of Houttuynia cordata. Drug Dev Ind Pharm 2014;40:1350-7.

9. Kharia AA, Singhai AK, Verma R. Formulation and evaluation of polymeric nanoparticles of an antiviral drug for gastroretention. Int J Pharm Sci Nanotechnol 2012;4:1557-62.

10. Munawar AM, Jaweria TMS, Kishor M, Ellen KW. An overview of chitosan nanoparticles and its application in non-parenteral drug delivery. Pharmaceutics 2017;9:1-26.

11. Barkat MA, Mujeeb M. Comparative study of Catharanthus roseus extract and extract loaded chitosan nanoparticles in alloxan-induced diabetic rats. Int J Biomed Res 2013;4:670-8.

12. Bora J, Syiem D, Bhan S. Methanolic flower extract of Phlogacanthus thyrsiflorus nees. Attenuates diabetic nephropathy in alloxan-induced diabetic mice. Asian J Pharm Clin Res 2018;11:113-6.

13. Pal S, Gautam S, Mishra A, Maurya R, Srivastava AK Antihyperglycemic and antidyslipidemic potential of Ipomoea batatas leaves invalidated diabetic animal models. Int J Pharm Pharm Sci 2015;7:176-86.

14. Nagalakshmi K, Sujatha S. Nanoencapsulation augments release efficacy and glucose tolerance of 14-deoxy, 11, 12-didehydro, andrographolide loaded polycaprolactone nanoparticles in streptozotocin-nicotinamide induced type 2 diabetes. Int J Appl Pharm 2017;9:51-3.

15. Komalavalli T, Packia LM, Muthukumarasamy S, Mohan VR. Antidiabetic and antihyperlipidaemic activity of Sonerila tinnevelliensis fischer whole plant in alloxan-induced diabetic rats. Int J Curr Pharm Res 2015;7:53-7.

16. Kaliamurthi S, Selvaraj G. Insight on solid lipid nanoparticles: characterization and application in diabetes mellitus. J Crit Rev 2016;3:11-6. 